NIM : 191320001

JURUSAN : ILMU AL-QUR'AN DAN TAFSIR

SEMESTER 3

\title{
HADIS TENTANG HUKUMAN
}

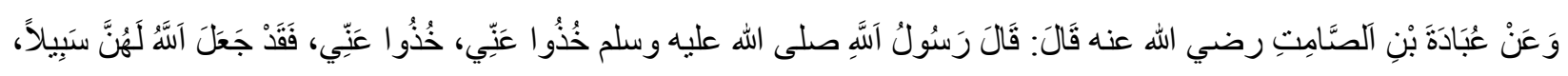

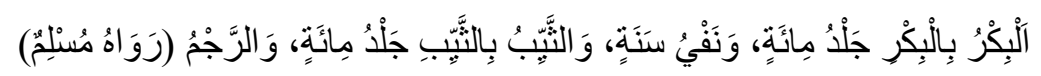

Dari Ubadah Ibnu al-Shomit bahwa Rasulullah Saw bersabda: “ Ambillah (hukum) dariku. Ambillah (hukum) dariku. Allah telah membuat jalan untuk mereka (para pezina). Jejaka berzina dengan gadis hukumannya seratus cambukan dan diasingkan setahun. Duda berzina dengan janda hukumannya seratus cambukan dan dirajam.” (HR. Muslim No. 993)

Penjelasan : maksudnya ialah jika ada yang berzina maka hukumlah dengan hukuman dari Rasulullah tersebut dan lakukannya agar hukum tersebut tetap ada. Bagi orang yang belum menikah ialah dengan seratus cambukan dan diasingkan setahun. Sedangkan yang sudah menikah, ataupun janda dan duda maka dicambuk pun sama seratus akan tetapi dengan pula rajam.

Intinya : lakukan lah hukum bagi orang yang berzina sesuai dengan Hukum dari Rasulullah Saw tersebut.

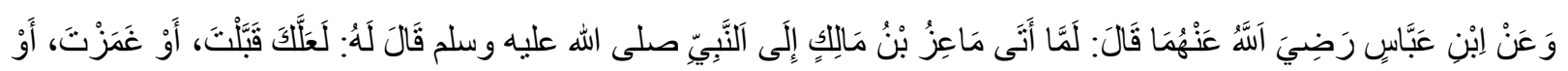

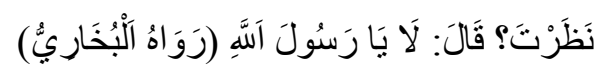

Dari Ibnu Abbas Ra berkata: Ketika Ma'iz Ibnu Malik menghadap Nabi Saw, beliau bertanya kepadanya: "Barangkali engkau cium, atau engkau raba, atau engkau pandang?". Ia berkata: "Tidak, wahai Rasulullah.” (HR. Bukhari No. 995) Kelanjutannya adalah: “Apakah engaku menyetubuhi?” Kali ini Rasulullah tidak menggunakan kata majas. Ma'iz tersebut menjawab: "Ya." Setelah itu maka Rasulullah memerintahkan agar ia dirajam. (HR. Ahmad dan Abu Daud)

Penjelasan : jika seorang tersebut mengaku maka segera untuk dilakukan hukumnya sesuai yang sudah ditentukan oleh Rasulullah Saw.

Intinya : Laksanakan hukum tersebut walaupun memang sangat berat dan tidak dilakukan di masa sekarang.

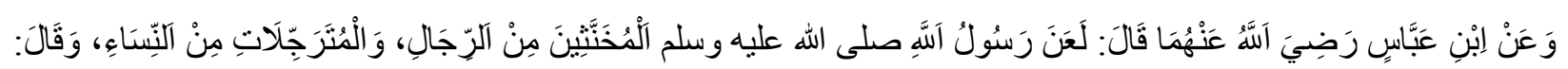

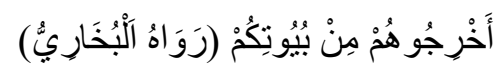

Dari Ibnu Abbas Ra berkata: Rasulullah Saw melaknat laki-laki yang bertingkah laku wanita, dan wanita bertingkah laku laki-laki. Beliau bersabda: "Usirlah mereka dari rumahmu." (HR. Bukhari No. 1004) 
Penjelasan : jadilah seorang laki-laki dengan kelakuan sesuai laki-laki jangan seperti perempuan, dan jadilah wanita yang berperilaku sesuai dengan jatidiri nya itu jangan berperilaku menyimpang karena Allah dan Rasulullah melaknat orang yang menyimpang dari jatidiri nya tersebut.

Intinya : Janganlah berperilaku seperti begitu karena itu sangat melaknat dan di benci oleh Allah Swt. Jikalau ada usir dari rumah kalian agar kalian tidak terkena laknat dan azab nya itu.

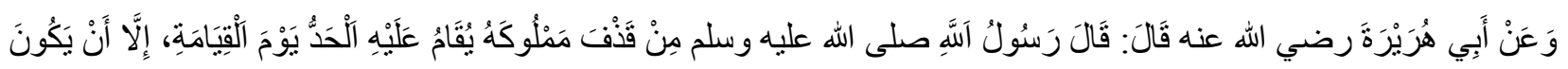

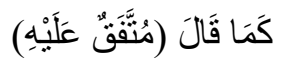

Dari Abu Hurairah Ra bahwa Rasulullah Saw bersabda: “Barangsiapa menuduh hambanya berzina, ia akan di hukum pada hari kiamat, kecuali jika hamba itu melakukan sebagaimana yang ia katakana.” (Muttafaq ‘Alaihi No. 1012)

Penjelasan : jangan lah kita asal menuduh jikalu memang belum ada bukti dan kenyataan yang jelas dari orang yang kita tuduh tersebut, karena itu jikalau kita menuduh sangat mengerikan siksaan nya diakhirat kelak.

Intinya : janganlah bersuudzon kepada orang sebelum ada bukti dan pengakuan yang nyata.

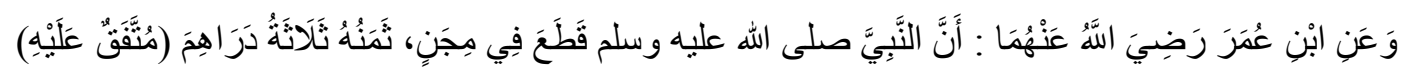

Dari Ibnu Umar Ra bahwa Nabi Saw pernah memotong (tangan pencuri) karena mengambil sebuah perisai seharga tiga dirham. (Muttafaq ‘Alaihi No. 1014)

Penjelasan : Jika memang ada pencuri yang mencuri harga berharga seharusnya secara hukum agama memang harus di potong untuk sekali mencuri yaitu dengan tangan tangan, jika mencuri kembali kaki kiri, dan selanjutnya dengan silang tersebut itu sesuai dengan hukum agama Islam.

Intinya : Sekali mencuri potong tangan kanan, dan ketika berulang kedua maka potong kaki kiri, ketika berulang kembali maka tangan kiri, dan ketika berulang kembali untuk ke empat maka potong kaki kanan.

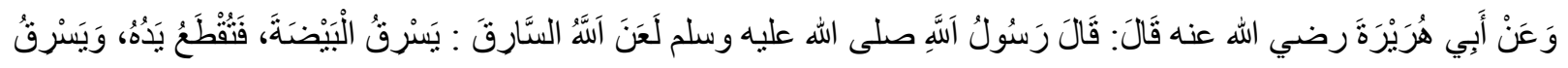

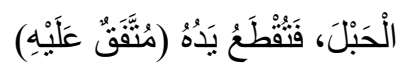

Dari Abu Hurairah Ra bahwa Rasulullah Saw bersabda: "Allah melaknat pencuri yang mencuri telur, kemudian dipotong tangannya, lalu mencuri tali dan di potong tangannya." (Muttafaq 'Alaihi No. 1015)

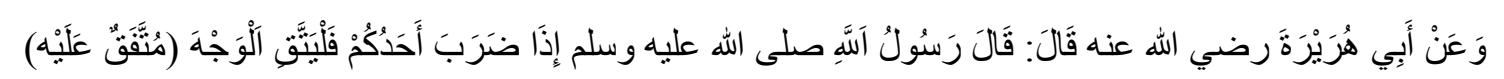

Dari Abu Hurairah bahwa Rasulullah Saw bersabda: "Apabila salah seorang di antara kamu memukul, hendaknya ia menghindari (memukul) wajah.” (Muttafaq ‘Alahi No. 1028)

Penjelasan : Rasulullah mengingatkan kepada kita bahwasannya melarang untuk seorang jikalau memukul itu tidak diperbolehkan wajah, dan hendaknya pula orang yang ingin dipukul tersebut harus bisa menghindar agar tidak terkena wajah. 
Intinya : Dilarang keras untuk memukul bagian wajah.

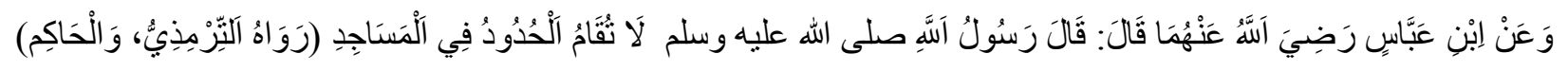

Dari Ibnu Abbas Ra bahwa Rasulullah Saw bersabda: “Tidak diperbolehkan melaksanakan hukuman di dalam Masjid.” (HR. At-Tirmidzi dan Hakim No. 1029)

Penjelasan : bahwa yang dimaksud di atas ialah siapapun orang nya itu dilarang sangat melakukan hukuman apapun itu di dalam masjid, karena Masjid ialah rumah Allah, rumah tempat ibadah dilarang keras.

Intinya : Dilarang untuk melaksanakan hukuman berupa apapun di dalam Masjid.

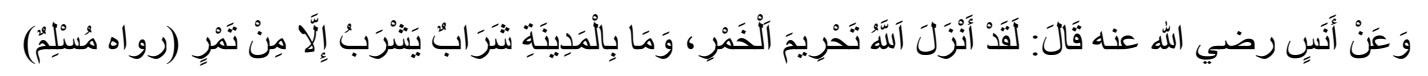

Dari Anas Ra berkata: Allah telah menurunkan ayat yang mengharamkan arak pada saat di Madinah tidak ada minuman keras yang diminum kecuali kurma. (HR. Muslim No. 1030)

Penjelasan : bahwasannya arak itu sebenarnya memang haram untuk dikonsumsi, karena sangatlah memabukkan dan membuat orang tidak sadarkan diri.

Intinya : Arak itu hukumnya Haram.

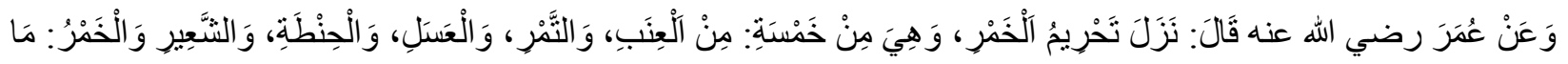

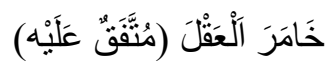

Dari Umar Ra berkata: telah turun ayat yang mengharamkan arak yang terbuat dari lima (bahan), yaitu anggur, kurma, madu, gandum, dan sya'ir. Arak ialah sesuatu yang dapat merubah pikiran (akal). (Muttafaq ‘Alaihi No. 1031)

Penjelasan : bahwa sebenarnya sudah dipastikan bahwa Arak itu sangat memabukkan dan arakpun dibuat dari lima bahan, yaitu anggur, kurma, madu, gandum, dan sya'ir jadi memang yang memabukkan itu semuanya adalah Haram.

Intinya : Arak terbuat dari lima bahan yang halal akan tetapi ketika sudah di minum ia menjadi memabukkan membuat pikiran orang berubah.

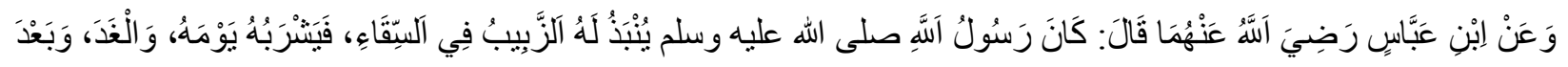

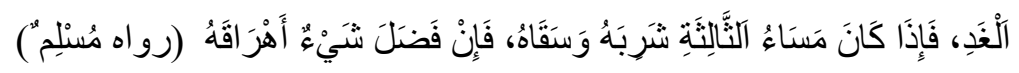

Dari Ibnu Abbas berkata: Rasulullah Saw selalu dibuatkan rendaman kismis dalam tempat minuman. Beliau meminumnya hari itu, esoknya dan esok lusanya. Bila pada sore hari ketiga masih ada, beliau meminumnya dan memberikannya kepada orang lain. Bila masih ada juga sisanya, beliau membuangnya. (HR. Muslim No. 1034)

Penjelasan : Jadi menurut hadis diatas bahwa jikalau makanan, minuman yang dimana sudah berhari-hari masih saja tersisa dan tidak habis, sebaiknya dibuang saja, atau tidak berikan kepada orang lain jikalau belum basi, ketika sudah diberikan dan tetapi masih ada maka buang saja. 
Intinya : makanan dan minuman yang sudah berhari-hari masih ada sisa sebaiknya dibuang saja.

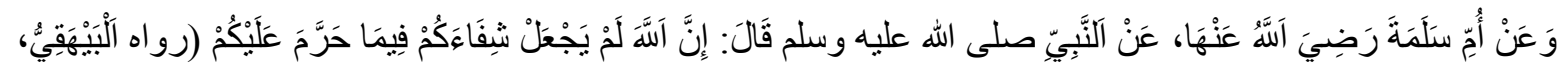

$$
\begin{aligned}
& \text { وَصَحَحَحَاُ إِبْنُ حِبَّنَان) }
\end{aligned}
$$

Dari Ummu Salamah Ra bahwa Nabi Saw bersabda: "Sesungguhnya Allah tidak menjadikan obat penyembuhmu dalam apa yang diharamkan kepadamu." (HR. Baihaqi dishahihkan oleh Ibnu Hibban No. 1035)

Penjelasan : bahwasannya Rasulullah itu bersabda obat yang menjadi penyembuh itu sebenarnya tidak ada yang diharamkan dan semua obat tersebut halal karena ingin menyembuhkan segala penyakit yang didierita.

Intinya : Obat yang menyembuhkan tersebut ialah tidak mengharamkan.

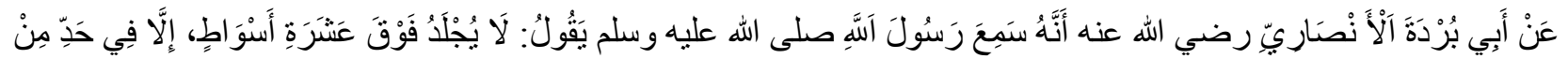

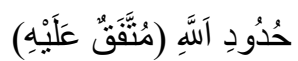

Dari Abu Burdah al-Anshori bahwa ia mendengar Nabi Saw bersabda: "Tidak boleh dicambuk lebih dari sepuluh cambukan, kecuali jika melanggar suatu had (hukuman) yang ditentukan Allah Swt." (Muttafaq ‘Alaihi No. 1037)

Penjelasan : bahwa jikalau ada orang yang dicambuk itu tidak boleh melebihi dari 10, akan tetapi jika ketentuan dari Allah Swt itu dilanggar dan melenceng dari yang ditentukan Allah Swt maka tidak apa-apa dicambuk melebihi dari 10 itu.

Intinya : Cambuklah orang yang salah ketika berbuat kesalahan, akan tetapi tidak melebihi dai 10 cambukan. 